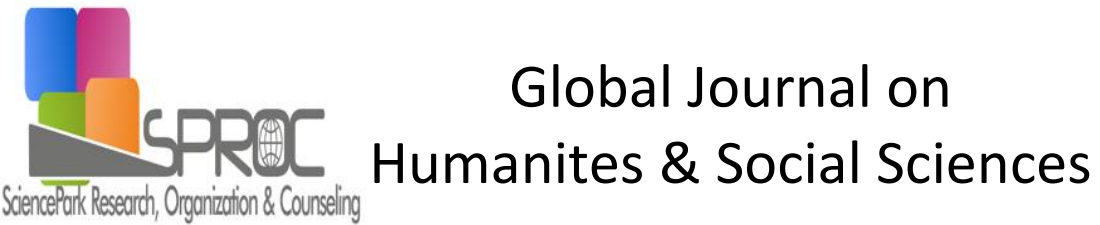

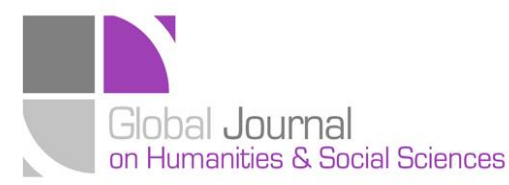

Vol 3 (2015) 289-297

Selected Paper of 4th World Conference on Design and Arts, (DAE-2015)

26-28 June 2015, St.Petersburg Christan University, St. Petersburg, Russia.

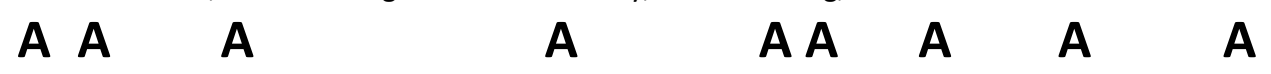

A $\quad$ A

A

A A Ahmet Keleşoğlu Faculty of Education, Institute of Educational Sciences, Konya Necmettin Erbakan University, Konya, 42090, Turkey.

A

A A

Ermiş, Y. (2016). İnvestigation of Social Responsibility Projects: a case study "every child matters", Global Journal on Humanites \& Social Sciences. [Online]. 03, pp 289-297. Available from: http://sproc.org/ojs/index.php/pntsbs

Received January 13, 2015; revised March 20, 2015; accepted May 31, 2015

Selection and peer review under responsibility of Prof. Dr. Milan Matijevic.

(C)2016 SciencePark Research, Organization \& Counseling. All rights reserved.

A

A

A

Social responsibility projects are works done in order to raise awareness to masses, draw attention to problems in the community and find necessary measures and solutions.As well as printed materials such as posters, billboards and brochures, social responsibility projects can be delivered to masses via virtual environments and mass media. Visual design products are visual communication tools that can be perceived easily, are able to influence people from all parts of society, can be applied in all spaces and areas, are able to easily connect with a large audience simultaneously in a virtual environment.UNICEF, the United Nations International Children's Emergency Fund, is an organization specialized in supporting children's rights, add sustainability to children's rights as permanent ethical principles and provide international standards for children's rights. The purpose of this study is to investigate the social responsibility project prepared by UNICEF for providing 2.2 Billion children around the world with every right using the slogan "Every child matters" in terms of elements of design discipline and pedagogical aspects such as clear and understandable design, reaching the target audience, use of correct images, psychological effects of colors used. Conclusion and recommendations were presented as a result of evaluations made regarding the findings of the study, which was conducted using qualitative research methods.

A

Keywords: social responsibility project, unicef, design principles, graphic design, visual communication $\mathbf{A}$

ADDRESS FOR CORRESPONDENCE: A Ahmet Keleşoğlu Faculty of Education, Institute of Educational Sciences, Konya Necmettin Erbakan University, Konya, 42090, Turkey. E-mail address: yesimm.kaya@hotmail.com,

Tel.: +905532510359 
Ermiş, Y. (2016). Investigation of Social Responsibility Projects: a case study "every child matters", Global Journal on Humanites \& Social Sciences. [Online]. 03, pp 289-297. Available from: http://sproc.org/ojs/index.php/pntsbs

Social responsibility projects are studies performed to raise awareness of masses, draw attention to problems in society, take necessary precautions and find solution thereto. Civil society organization is an organization type that works for benefit of society, contributes to the development of democracy, is non-profit, takes actions separate from government and that can affect political will and government by creating a public opinion on examining mutual purpose and targets of individuals (Commission of the European Communities, 2001). "Virtual 1" According to civil society organizations, social responsibility consists of voluntary studies ensuring sustainable development (Hirschland, 2003).

In classification by Geoffrey Lantos simplified by reinterpreting Archie Carll classification, three types of Corporate Social Responsibilities are referred: Charity-oriented Corporate Social Responsibility, Ethical Corporate Social Responsibility, Strategic Corporate Social Responsibility. Charity-oriented CSS is enlightened with a totally utilitarian mentality and attempts to be beneficial for society ruling out profit margin completely constitute "charity-oriented" CSS scope (Lantos, 2001). "Virtual 2"

UNICEF is an institution supported by United Nations General Assembly of which purpose is to support and defend child rights, ensure establishment of child rights as permanent ethical principles, meet basic needs of children and provide them environments in which they can develop to the most of their potentials, diminish childhood diseases and child deaths in situations such as war and natural disaster, bringing basic needs of children including those affected by HIV/AIDS to international standards as the expert and appointed institution. It gives priority to all children who have been subjected to all sorts of violence and abuse, to disabled children and to children and their families in environments of war, conflict and natural disaster. "Virtual 3"

It has been thirty years since standardized global and national statistical tables started to be given with the aim of presenting a detailed view of conditions of children by The State of the World's Children in "Every child counts" campaign of UNICEF. Consistent and reliable information relating to condition of children have a critical importance in terms of improvement of lives of children and all rights of all children should be accomplished. It continues studies on behalf of 2 . 2 billion children around the world. These data present realities to provide base to governments in their decisions and activities for improving lives of children. With obtained data, use of these data to provide positive change by decision makers and finding required data to question responsible people for children and societies are provided. How many children will die in the first year following their birth? How many will not be able to see his/her 5th year? Can they take basic vaccines and medication for protection against diseases bothering particularly little children? Can they take required nutrients for physical and mental development? Do they have clean water to drink and have shower and safe and hygienic toilets? How many percent of children can start primary education and how many can continue to secondary school? How many people are made to work or marry as a child? Do children reach their adolescence periods equipped with information to protect themselves against HIV? Data acquired in this study were collected for seeking answers for problems such as genital mutilation / amputation in women. UNICEF has published its first report in 2013 that analyzes by summarizing data of 29 countries this implementation is commonly seen in addition to new data presented relating to little female children below 15 . UNICEF and others prepare and apply many one and multi-country studies in this field. Recent studies made in Cambodia, Haiti, Kenya, Malawi, United Republic of Tanzania And Zimbabwe are among examples. "Virtual 4"

To ensure reaching of social responsibility projects to masses, virtual platforms and mass media can be utilized as well as printed materials such as poster, billboard and brochure. Visual design products are important visual communication means in that they are readily understandable, they can have effect on people from every walk of life, they have application easiness in every place and area and they can easily establish a bond simultaneously and with large masses in visual platform. Graphic design has penetrated into every field of life with many functions such as to mention someone about 
Ermiş, Y. (2016). Investigation of Social Responsibility Projects: a case study "every child matters", Global Journal on Humanites \& Social Sciences. [Online]. 03, pp 289-297. Available from: http://sproc.org/ojs/index.php/pntsbs

your thoughts, to gain money, for political purposes, to sell objects or ideas and for publicity purposes, in information design, to make everything more transparent, even to ease daily life and to enable people to understand data. Graphic Design: It has a potential to enable significant exchanges among people and to change course of society by declaring something of importance to millions of people and a communication is enabled by reaching masses via graphic design language (Twemlow, 2011).

Images are graphic items bringing the design into life. Images have an important role in transmitting message whether they are main focus points or ancillary items of a page as they constitute visual identity. Basic page layout principles enable designer to use images consistently and also creates harmony with other images (Ambrose \& Harris, 2011).

Banner design should be perceivable, message should be striking and be transmitted rapidly, message should be emotional and stimulating, words should be short and understandable, message should aim operationalizing rather than informing, word count should be lowered, visual arrangement should be simple and striking, design should be original, it should be differentiated from banners of similar organizations, design and typography should be purified of unnecessary details, too much picture and writing to cause visual conflict should be discarded, only one image should be used, effect should be increased by decreasing details in the picture, images should be large for easy perception and color should be symbolic, specific and striking (Teker, 2009).

One subject to pay attention in a good design is page layout. Page is an area where images and texts are presented. Thus, designer should take aim and target group of publication into consideration to form page layout effectively. Grid is a tool that enables and facilitates decision making for arrangement and incorporation of design items. Decreasing number of used visual images and placing them in a grid system suggest orderliness in design, creating compact planning, understandability and clearness and thus this orderliness raises feeling of reliability, adding credibility to the information (Ambrose \& Harris, 2011). According to Neville Brody, page grid forms basic structure in that everything depends on it. Grid in forming page layout in graphic design is as important as scaffold, beams of a building, in construction sector. Enough space should be provided connected properly to avoid distraction from middle of the page to the right and to the left as if things were scattered. Encircling without disrupting the flow on passing from one area to another is required (Wozencroft, $1988 ; 1)$. It is base of graphic design to understand how images and writings are placed in page layout. The form of composing can contribute to the text and improve perception of and attitude towards it and this can affect reading and even perception of the text (Ambrose \& Billson, 2013).

When a visual expression is prepared, it is beneficial to make use of verbal expressions, if necessary. Color, style, font or variability between lines made to verbal expressions without preventing meaning loss of visual expression can actually increase effectiveness of visual expression (Perkmen, Öztürk, 2009; 35). Typography as one of design items means presentation of a written idea visually. Choice of visual form affects readability of the idea and emotions of readers about the idea significantly. Typography can create a neutral effect or an effect stimulating emotions, can symbolize artistic, political or philosophical entities or can express identity of an organization (Ambrose \& Harris, 2013). Typography has become a discipline that conveys message with selection and editing of typefaces together with design and that is constantly open to development (Wigan, 2012). Arrangements made on a colorful base harden reading. In a visual design preparation, image and base color contrasts should be utilized to enable readability and not to strain eyes. If items in the visual are dark colored, base color should be light colored or vice versa (Perkmen \& Öztürk, 2009).

Color as a design item and symbolic item is a formation and exists with light. Only color can convey message or direct behaviors. Color is an important factor in organizing both design item and visual hierarchy. With color and tone values, we emphasize or de-emphasize shapes and typography. It is important to manage colors and their relationship. Colors have visual, sensual, informational, aesthetical, symbolical and psychological effects. As colors have different wavelengths they also have definitions such as visibility, warm and cold color. It has been determined that pure colors are easily perceived and they raise feelings of cleanness and peace. Warm colors consisting of yellow, orange 
and red of which wavelengths are high raise feeling of intimacy while cold colors such as blue, green and purple raise feeling of distantness. A designer having these color knowledge can overcome visual depth problems within visual composition. It should also be considered during formation of design that colors have interculturally different meanings. For example, orange color symbolizing joy and energy in the West is defined as a sacred color in India in the East (Uçar, 2004).

\section{A A}

\subsection{Research Model}

This study has a scanning model and is a descriptive study.

\subsection{Study Group}

Prepared questionnaire was applied to 10 participants in total including 6 men and 4 women having an age ranging from 34 to 60 and 5 of these participants work in Konya Selçuk University and 5 of them work in Necmettin Erbakan University. Three of academic staff participated work in Faculty of Education, Painting Department, one of them works in Education Department, Department of Psychological Counseling and Guidance and six of them work in Faculty of Fine Arts, Painting Department while 2 of participants are professors, 3 of them are Associate Professors, 4 of them are Assistant Professors and one is an academic.

\subsection{Tool for Data Acquisition}

Data of the research were collected by a questionnaire and a questionnaire of 10 questions was applied to the academics participated to this research, wherein the answers of 8 questions in the questionnaire were as Yes or No, and 2 of them were open-ended.

\subsection{Data Analysis}

During the analysis of the research data the results obtained from the questionnaires were given as frequency and percent values. Expression and drawings were analyzed by providing the evaluation criteria developed by the researchers as frequency and percent values.

Table 1.Aindings And CommentsA

\begin{tabular}{lll}
\hline & Frequency & Percent \\
\hline Yes & 8 & 80 \\
No & 2 & 20 \\
Total & 10 & 100 \\
\hline
\end{tabular}

A A A AWhen Table 1 is examined, in which the results relating to the answer for the question "Is the message of the Social Responsibility Project sufficient for reaching the intended population?" contained in the questionnaire are evaluated, the rates for the answers "Yes" and "No were found as $80 \%$ and $20 \%$, respectively and it was concluded that the academics participated to the questionnaire thought that the message which is tried to be given by Social Responsibility Project of Unicef called "Every Child Counts" had reached the intended population. 
Ermiş, Y. (2016). İnvestigation of Social Responsibility Projects: a case study "every child matters", Global Journal on Humanites \& Social Sciences. [Online]. 03, pp 289-297. Available from: http://sproc.org/ojs/index.php/pntsbs

Table 2. Findings And Comments

\begin{tabular}{lll}
\hline & Frequency & Percent \\
\hline Yes & 9 & 90 \\
No & 1 & 10 \\
Total & 10 & 100 \\
\hline
\end{tabular}

A A A When Table 2 is examined, in which the results relating to the answer for the question "Are visuals selected for Social Responsibility Project suitable for the campaign context?" contained in the questionnaire are evaluated, the rates for the answers "Yes" and "No were found as $90 \%$ and $10 \%$, respectively and it was concluded that the academics participated to the questionnaire found that visuals selected for Social Responsibility Project of Unicef called "Every Child Counts" were suitable for the campaign context, but one participant criticized that too many black child visuals were used in the visuals.

Table 3. Findings And Comments

\begin{tabular}{lll}
\hline & Frequency & Percent \\
\hline Yes & 10 & 100 \\
No & 0 & 0 \\
Total & 10 & 100 \\
\hline
\end{tabular}

A A A AWhen Table 3 is examined, in which the results relating to the answer for the question "Is the slogan of 'Every Child Counts' selected for Social Responsibility Project an appropriate choice?" contained in the questionnaire are evaluated, the rates for the answers "Yes" and "No were found as $100 \%$ and $0 \%$, respectively and it was concluded that the academics participated to the questionnaire thought that the slogan selected for Social Responsibility Project of Unicef called "Every Child Counts" was suitable for the campaign and that it became a slogan to be accepted by everyone.

Table 4. Findings And Comments

\begin{tabular}{llc}
\hline & Frequency & Percent \\
\hline Yes & 9 & 90 \\
No & 1 & 10 \\
Total & 10 & 100 \\
\hline
\end{tabular}

A

A A A AWhen Table 4 is examined, in which the results relating to the answer for the question "Are colors used in the design of Social Responsibility Project compatible with the campaign context?" contained in the questionnaire are evaluated, the rates for the answers "Yes" and "No were found as $90 \%$ and $10 \%$, respectively and it was concluded that the academics participated to the questionnaire found that colors used on campaign posters prepared for Social Responsibility Project of Unicef called "Every Child Counts" were compatible with the context, but they suggested that more striking colors could be used in the spot sentences.

Table 5. Findings And Comments

\begin{tabular}{lll}
\hline & Frequency & Percent \\
\hline Yes & 8 & 80 \\
No & 2 & 20 \\
Total & 10 & 100 \\
\hline
\end{tabular}


A A A AWhen Table 5 is examined, in which the results relating to the answer for the question "Is the typography used in the design of Social Responsibility Project compatible with the campaign?" contained in the questionnaire are evaluated, the rates for the answers "Yes" and "No were found as $80 \%$ and $20 \%$, respectively and it was concluded that the academics participated to the questionnaire found that the typographic design used on the campaign poster prepared for Social Responsibility Project of Unicef called "Every Child Counts" was suitable, but two participant who said No criticized that a more stressed typography could be used although one participant who said Yes suggested that the type size could be greater.

Table 6. Findings And Comments

\begin{tabular}{lll}
\hline & Frequency & Percent \\
\hline Yes & 9 & 90 \\
No & 1 & 10 \\
Total & 10 & 100 \\
\hline
\end{tabular}

A

A A A AWhen Table 6 is examined, in which the results relating to the answer for the question "Are point size, font, line length and line space used in the design of Social Responsibility Project suitable?" contained in the questionnaire are evaluated, the rates for the answers "Yes" and "No were found as $90 \%$ and $10 \%$, respectively and it was concluded that the academics participated to the questionnaire found that Are point size, font, line length and line space used on campaign poster prepared for Social Responsibility Project of Unicef called "Every Child Counts" were mostly suitable, but one participant who said No suggested that adjusting the page layout as being justified instead of being right justified would have a better result.

Table 7. Findings And Comments

\begin{tabular}{lll}
\hline & Frequency & Percent \\
\hline Yes & 8 & 80 \\
No & 2 & 20 \\
Total & 10 & 100 \\
\hline
\end{tabular}

A

A A A AWhen Table 7 is examined, in which the results relating to the answer for the question "Are point size, font, line length and line space used in the design of Social Responsibility Project suitable?" contained in the questionnaire are evaluated, the rates for the answers "Yes" and "No were found as $80 \%$ and $20 \%$, respectively and it was concluded that the academics participated to the questionnaire found that the layout (page layout) and grid (grid arrangement system) used in the campaign prepared for Social Responsibility Project of Unicef called "Every Child Counts", but one participant who said Yes stated that resolution was not good and 2 participants who said No criticized that the line breaks were not aligned in the page layout.A

Table 8. Findings And Comments

\begin{tabular}{lll}
\hline & Frequency & Percent \\
\hline Yes & 9 & 90 \\
No & 1 & 10 \\
Total & 10 & 100 \\
\hline
\end{tabular}


Ermiş, Y. (2016). İnvestigation of Social Responsibility Projects: a case study "every child matters", Global Journal on Humanites \& Social Sciences. [Online]. 03, pp 289-297. Available from: http://sproc.org/ojs/index.php/pntsbs

A A A AWhen Table 8 is examined, in which the results relating to the answer for the question "Is the design selected for Social Responsibility Project suitable for the intended use?" contained in the questionnaire are evaluated, the rates for the answers "Yes" and "No were found as $90 \%$ and $10 \%$, respectively and it was concluded that the academics participated to the questionnaire agreed that the design prepared for Social Responsibility Project of Unicef called "Every Child Counts" was suitable for the intended use.

Table 9. The answers given by academics to an open-ended question "How do you think visuals selected for Social Responsibility Project affect pedagogically?" are tabulated.

f $\%$

Using too much visuals for the black race and showing these people 3 30 as a second-class human being are negative as these create a pathetic image on children from this race.

All kinds of information relating to the environment in which children 3 30 live is provided and also the selected visuals are convenient and attractive in terms of stimulating the visual perception of people, I think they will raise awareness, I found it positive.

It will be more democratic to use illustration instead of photos and to 1 minimize racial emphasis.

Effective representation of indicators that are pointed out without 2 discriminating between race, language and religion visually in a simple way is capable of reaching all walks of life, thus it likely provides awareness. 
Ermiş, Y. (2016). İnvestigation of Social Responsibility Projects: a case study "every child matters", Global Journal on Humanites \& Social Sciences. [Online]. 03, pp 289-297. Available from: http://sproc.org/ojs/index.php/pntsbs

Table 10. The answers given by academics to the question "What are your opinions about Social Responsibility Projects of UNICEF?" are tabulated.

\begin{tabular}{|c|c|c|}
\hline & $\mathrm{F}$ & $\%$ \\
\hline $\begin{array}{l}\text { I think that they are the projects which have to be continued as } \\
\text { they focus on children's rights and protection, and make real } \\
\text { purposes thereof, and I found them positive. }\end{array}$ & 4 & 40 \\
\hline I think that all social responsibility projects are useful. & 1 & 10 \\
\hline $\begin{array}{l}\text { I find social responsibility projects of Unicef are positive, } \\
\text { however I think that much positive results for all world's } \\
\text { children could be obtained by further improving these projects. }\end{array}$ & 1 & 10 \\
\hline $\begin{array}{l}\text { Detailed reflection of problems by paying equal attention to all } \\
\text { world's children indiscriminating of race, language and religion } \\
\text { in social responsibility projects of Unicef having a different } \\
\text { importance for children will enhance attention relating to the } \\
\text { project. }\end{array}$ & 2 & 20 \\
\hline I am concerned about applicability of these projects. & 2 & 20 \\
\hline Total & 10 & 100 \\
\hline
\end{tabular}

A

A

\section{A A}

It was found that the message of Social Responsibility Project executed by UNICEF with a slogan "Every Child Counts", selected visuals, slogan, color used and typography choice and font, point size and line length were suitable for the intended use, and that the campaign was satisfactory in terms of giving information. It was criticized that using too much photos belonging to the black race created a negative perception for these children and thus it was suggested that an illustration could be used at times while highlighting the importance of treating equally to all world's children in this kind of social responsibility projects without discriminating between race, language and religion. It is specified that these kinds of projects are the ones which have to be continued as they focus on children's rights and protection, and make real purposes thereof. It is possible to facilitate enabling the campaign to reach its goal by having a context and message based on the user that is, intended population on visual designs used in social responsibility projects, taking account the page layout, selecting the image used appropriately, and by designing the color and typography such that they will be equal in visual integrity and they do not reduce the readability. I think that these evaluations will be useful in determining how could be made these social responsibility projects to reach more mass strikingly by contributing to the instructive and guiding poster design used in the campaign projects of UNICEF in applying social responsibility.

\section{A}

Ambrose, G., \& Billson, A. (2013). Approach and Language. Literatür. Publishing: Istanbul.

Ambrose, G., \& Harris, P. (2011). Layout. Literatür Publishing: Istanbul.

Ambrose G., \& Harris P. (2013). The Fundamentals of Creative Design Literatür. Publishing: Istanbul.

Hirschland, M.J. (2003). Corporate Social Responsibility Network: Assessing the Private governance of Public Goods, University of Colorado, ABD.

Perkmen, S., \& Öztürk A. (2009). Multimedia and Visual Design. 1st Edition Profil Publishing Istanbul.

Teker, U. (2009). Graphic Design and Advertising, Yorum Sanat Publishing, Istanbul. 
Ermiş, Y. (2016). İnvestigation of Social Responsibility Projects: a case study "every child matters", Global Journal on Humanites \& Social Sciences. [Online]. 03, pp 289-297. Available from: http://sproc.org/ojs/index.php/pntsbs

Twemlow, A. (2011). How to Graphic Design. 2nd Edition. Yem Publishing: Istanbul.

Uçar, T. (2004). Visual Communications and Graphic Design. 4th Edition. Inkılap Publishing : İstanbul.

Wigan, M. (2012). The Visual Dictionary of Illustration. (Translation Mehmet Emin Uslu). Ömür Publishing : Istanbul.

Wozencroft, J. (1988). Graphic Arts. Neville Brody with Interview on Typography. Grafikerler Meslek Kuruluşu. Yazılar. July number: 9. Mataş Publishing.VInternet Sources

Commision of the European Communities. (2001). Green paper: Promoting a european framework for corporate social responsibility. http://ec.europa.eu/employment social/publication/2001/ke3701590 en.pdf "Virtual 1"

Lantos, Geoffrey P. (2001) The Ethicality of Altruistic Corporate Social Responsibility. http://www.emeraldinsight.com/.Journal of Consumer Marketing "Virtual 2"

Received from: https://www.unicefturk.org/index.php?p=unicefnedir\&sub=calismalar07/06/201501.30 "Virtual $3 "$

Received from: http://www.unicef.org.tr/files/bilgimerkezi/doc/Unicef\%20SOWC\%202014\%20web.pdf. "Virtual $4 "$ 